\title{
Otizm Spektrum Bozukluğu Olan Çocuklarda Kaynaştırma Eğitiminin Uzman ve Ebeveyn Bakış Açısı ile İncelenmesi
}

\author{
Examination of Mainstreaming Education in Autism Spectrum Disorder Children by Expert and
} Parental Perspective

\section{Esra ÜNSAL ${ }^{1}$, Çiğdem ÖKSÜZ ${ }^{2}$}

${ }^{1}$ Ergoterpist, Hacettepe Üniversitesi Sağlık Bilimleri Fakültesi Ergoterapi Bölümü, Ankara

${ }^{2}$ Doç. Dr., Hacettepe Üniversitesi Sağlık Bilimleri Fakültesi Ergoterapi Bölümü, Ankara

\section{Öz}

\begin{abstract}
Amaç: Bu araştırma Otizm Spektrum Bozukluğu olan çocuklarda kaynaştırma eğitiminin uzman ve ebeveyn bakış açısı ile değerlendirilmesi amacıyla planlanmıştır. Gereç ve Yöntem: Araştırmaya çocukları kaynaştırma eğitimi almakta olan, OSB olan çocuğa sahip 4 ebeveyn ve bir Psikolog ve bir Ergoterapist uzman dahil edilmiş̧ir. Araşırıma nitel araştırma yöntemi kullanılarak gerçekleştirilmiştir. Sonuçlar: Araştırmamızda kaynaştırma eğitim uygulamaları ve çocuklara katkıları düşünüldüğünde bireysel farklılıklar ortaya koyulmuştur. Öğretmen tutumlarının olumlu veya olumsuz niteliğe sahip olabilen katkıları bu kapsamda en çok dikkat çekilen konu başı̆ı̆ı olmuştur. Ayrıca okul yönetimi ve destek personeli tutumları hakkında bireylerin eksik farkındalıkları üzerinde durulmuştur. Toplumsal seviye uygulama prosedürlerinin daha açıklayıcı ifade edilmesi gerektiği sonucu çıkarıımışır. Tartışma: Araştırma sonuçlarımızdan elde edilen bilgiler ışığında kaynaştırma eğitiminde toplumsal bakış açısının iyileştirilmesi intiyacı ortaya çıkmıştı. Çocuğun bireysel intiyaçları ve davranış şekillerinin belirlenmesi ve bu alanda çalışan meslek gruplarının bu konuda bilgilendirilmesi ile kaynaştırma eğitiminde kalitenin artırılabileceği düşünülmektedir.
\end{abstract}

Anahtar Kelimeler: Katııım; Kaynaştırma eğitimi; Otizm

\section{ABSTRACT}

Purpose: The study was designed to evaluate the mainstream education by parents and experts perspective in children with autism spectrum disorders ..Materials and Method: Four parents who have children with ASD, taking mainstream education and two experts with psychologists and occupational therapists were included in the study. The study was carried out using qualitative research method. Results: In our study, individual differences have been revealed when considering the mainstreaming education practices and contributions to children. Contributions that can be positive or negative qualities of teacher attitudes have been the subject of most of attention in this context. In addition, the lack of awareness of the individual about school management and the attitudes of the support staff are emphasized. The conclusion is that social level implementation procedures should be expressed more explicitly. Conclusion: With the data obtained by the research, it has been concluded that there is a need to improve the societal perspective. It is thougth that by identifiying the child's individual needs and behavior patterns and informing the professionals working in this field, quality of mainstreaming education can be increased.

Key Words: Mainstreaming Education; Participation; Autism 
Kaynaştırma eğitimi; eğitimde eşitlik ilkesi ve bireylerin kendileri için en az kısıtlayıcı çevrede eğitilmesi gerektiği görüşünden oluşturulmuştur. T.C. Anayasa' sının 42. Maddesi "Kimse eğitim ve öğrenim hakkından yoksun bırakılamaz. Devlet, maddi imkanlardan yoksun başarılı öğrencilerin, öğrenimlerini sürdürebilmeleri amacı ile burslar ve başka yollar ile gerekli düzenlemeleri yapar. Devlet durumları sebebiyle özel eğitime intiyacı olanları topluma yararlı kılacak tedbirler alır." hükmü ile Türkiye Cumhuriyeti vatandaşlarının eğitim ve öğretimden yararlanma hakkı olduğunu ve fırsat eşitliğini vurgulamaktadır, ayrıca özel gereksinimli bireylerin intiyaçlarına yönelik gerekli yönlendirmelerin ve tedbirlerin alınacağını ifade etmektedir (Çetinkaya, 2012).

Kaynaştırma yoluyla eğitimin amacı; özel eğitime intiyacı olan bireylere destek eğitim hizmetleri de verilerek yetersizliği olmayan akranlarıyla bir arada aynı ortamda eğitimlerini sürdürmelerini sağlamaktır. Bu uygulamalar kapsamında özel eğitime intiyacı olan bireyler, kaynaştırma yoluyla eğitimlerini, yetersizliği olmayan akranları ile birlikte aynı sınıfta, tam zamanlı sürdürebilecekleri gibi özel eğitim sınıflarında yarı zamanlı olarak da sürdürebilirler (Kargın T., 2004)

Görme engelli, işitme engelli, ortopedik engelli, dil ve konuşma güçlüğü olan engelliler, öğrenme güçlüğü olan engelliler, üstün ve özel yetenekliler ve uyum güçlüğü olan çocuklar kaynaştırma eğitimi alabilmektedirler. Otizm Spektrum Bozukluğu (OSB) gruplar içerisinde en yeni tanılanmış gruptur (Girli, 2007).

OSB olan bireylerin erken çocukluk döneminden itibaren başlayıp ilkokul ve ortaokul eğitimini kapsayan okul dönemi ve yetişkinlik dönemindeki iş ve mesleki eğitim programlarını da içeren yaşam boyu süren bir özel eğitim hizmeti alabilmeleri gerekmektedir. OSB' li bireyler, özel eğitim uygulama merkezinde, özel eğitim iş uygulama merkezinde, özel eğitim sınıflarında ya da normal gelişim gösteren akranlarıyla birlikte kaynaştırma sınıflarında eğitim görmektedirler. Ayrıca özel eğitim ve rehabilitasyon merkezlerinde destek eğitim alabilmektedirler. OSB olan bireylere eğitim hizmetleri MEB tarafından verilmekte olup kaynaştırma hizmetleri de bu kapsamda bakanlık tarafından gerçekleştirilmektedir (Erden, G., Akdur, S., Angın, E., Er, E., Aslan, B., 2014)

Çocukların davranışlarının şekillenmesi çevrelerindeki yetişkin ve akranların davranışlarının gözlenmesi ve taklit edilmesi ile şekillenmektedir. Bu nedenle de çocuğun normal sınıflarda bulunması toplum beklentilerine uygun davranışlarda gelişme fırsatı sağlamaktadır (Ulutaşdemir, 2007).

Literatürde kaynaştırma eğitiminde ebeveynler, öğrenciler, yöneticiler, öğretmenler ve eğitim ortamlarından kaynaklanan çeşitli sorunlar yaşandığı ortaya konmaktadır (Koçyigit S., 2015). Mevcut sorunlar olarak literatürde OSB' de kaynaştırma eğitiminde ailelerin ve öğretmenlerin bakış açıları, yaratıcı eğitim çevresi, pozitif akran ilişkilerinin desteklenmesi ve yasal politikalar gibi başlıklara dikkat çekilmektedir. Ailelerin sahip olduğu endişelerin giderilmesi, kaynaştırmanın güçlendirilmesi amacıyla stratejiler geliştirilmesi ve katılımın iyileştirilmesi için politikacılar, öğretmenler, okul yöneticileri ve terapistler en iyi adres olarak gösterilmektedir (Falkmer et al., 2015). Literatürde kaynaştırma sürecinin güçlendirilmesinde okullarda gerçekleştirilen rehabilitasyon hizmetleri önemli uygulamalar olarak vurgulanmaktadır (Bilaver et al., 2016).

Kaynaştırma uygulamalarının kalitesini arttırmak için mevcut sürecin içinde olan bireyler tarafından değerlendirilmesi önemlidir. Verilen çözüm önerileri ve literatürde yapılan araştırmalar dikkate alındığında uzmanlar ve ebeveynlerin görüşlerinin bir arada alındığı çalışma örneği bulunmamaktadır. Çalışmamız ile kaynaştırma eğitimi alan OSB' li bireylerin yaşadıkları deneyimlerin ebeveyn ve uzmanların değerlendirmeleri ile ortaya koyulması ve bireylerin kaynaştırma uygulamalarına hakkında görüşlerinin incelenmesi amaçlanmaktadır.

\section{GEREÇ VE YÖNTEM}

Veri Toplama Süreci

Araştırmamız çerçevesinde OSB' li çocukların kaynaştırma eğitim süreçleri hakkında bilgi edinmek amacıyla OSB' li çocuğa sahip ebeveynler ve kaynaştırma eğitim konusunda uygulamalar yapmakta olan uzmanlarla görüşme yapılmıştır.

Araştırmamıza; çocukları Hacettepe Üniversitesi Ergoterapi Bölümü Duyu Bütünlüğü Ünitesi'nde tedavi alan ve Milli Eğitim Kurumlarına bağlı okullarda kaynaştırma eğitimi almakta olan, OSB tanılı çocuğa sahip dört ebeveyn dahil edilmiştir. Uzman görüşleri kapsamında ise Ankara ili, Çankaya ilçesinde Özel Eğitim ve Rehabilitasyon Merkezi' nde çalışmakta olan Psikolog ve Ergoterapist iki uzman ile görüşme gerçekleştirilmiştir. Ebeveyn görüşmelerinden üçü Hacettepe Üniversitesi Ergoterapi Bölümünde yapılmış olup biri ev ziyareti ile gerçekleştirilmiştir. Uzman görüşmeleri ise bireylerin çalıştıkları kurumda gerçekleştirilmiştir. 
Verilerin toplanması niteliksel veri toplama tekniklerinden yarı yapılandırılmış görüşme yöntemi ile gerçekleştirilmiştir. Veriler Nisan-Mayıs 2016 tarihleri arasında toplanmıştır. Ebeveyn görüşmelerinde kaynaştırma eğitiminin yeterliliği, eğitimin kuvvetli ve zayıf yanları, çocuklara katkıları, süreç içerisinde etkileşim içinde olunan bireylerin (uzman, diğer çocuklar ve ebeveynleri, okul yöneticileri) tutum ve davranışları ve yasal süreçler sorgulanmıştır. Uzmanlar ile yapılan görüşmelerde kaynaştırma eğitimi uygulamalarının yeterliliği, eğitimin kuvvetli ve zayıf yanları, çocuklara katkıları, uygulama paydaşlarının tutum ve davranışları, yasal süreçler sorgulanmıştır.

\section{Veri Analiz Süreci}

Bireyler görüşme öncesinde araştırma hakkında bilgilendirilmiş olup ardından sosyo demografik bilgiler ve aydınlatılmış gönüllü onam formunun imzalatılması ile görüşme başlatılmıştır. Görüşmeler izin alınabilen katılımcılarla ses kaydı alınarak gerçekleştirilmiştir. Alınan ses kayıtları deşifre edilerek veriler arasına dahil edilmiştir. Görüşmeler esnasında ses kaydı için izin alınamayan katılımcılarla yapılan görüşme verileri araştırmacı tarafından görüşmenin tamamı elle kaydedilerek elde edilmiştir.

Veri analiz sürecinde ilk olarak görüşme kayıtları ve araştırmacı notları çözümleme çalışmaları gerçekleştirilmiştir. Elde edilen veriler nitel araştırmalarda sıklıkla tercih edilen içerik analiz yöntemi kullanılarak analiz edilmiştir. Bu süreçte uzman ve ebeveynlerden elde edilen bilgiler kodlanarak temalar oluşturulmuştur. Yapılan içerik analizi sonucunda; bireysel seviye, sınıföğretmen seviyesi, okul seviyesi ve toplumsal seviye başlıkları temalar olarak kabul edilmiştir.

\section{SONUÇ}

Çalışmamızda görüşme gerçekleştirilen Ergoterapist katılımcımız iki senelik iş tecrübesine sahip olup OSB'de kaynaştırma eğitimini destekleyici uygulamaları da içermekte olan çalışmalar gerçekleştirmektedir. Psikolog katılımcımız üç senelik iş tecrübesine sahiptir. Yüksek lisans eğitimi ile akademik çalışmalara devam etmekte olup aynı zamanda uygulamaları kapsamında kaynaştırma eğitimi konusu ile özel olarak ilgilenmektedir.

Katılımcı ebeveyn profilleri ise tablo 1 'de belirtilmiştir. Ebeveyn ve uzmanların ismi açıkça belirtilmemiş olup tüm katılımcılar için katılımcı 1 , katılımcı 2 ... katılımcı 6 ifadeleri kullanılmıştır. Katılımcı 1, katılımcı 2 ... katılımcı 4 ifadeleri ebeveynleri, katılımcı 5 Psikolog'u ve katılımcı 6 Ergoterapist'i ifade etmektedir.

Yapılan içerik analizinden elde edilen bireysel seviye, sınıf/öğretmen seviyesi, okul seviyesi ve toplumsal seviye temalarına ait kodlar Tablo 2'de gösterilmiştir.

Bireysel seviye; Bu tema çocuğun yaşı veya tanısına ilişkin bireysel farklılıkları içeren katılımcı görüşlerini içermektedir. Ebeveynler ve uzmanlar kendilerine yöneltilen çocuğun yaşı, tanısı gibi faktörlerin kaynaştırma eğitimine etkilerine cevap arayan araştırma sorularına deneyimlerinden örnekler vererek etkilemekte olduğunu belirtmişlerdir. Katılımcı 1 şöyle belirtmektedir: "Oğlum sadece biraz dikkat dağıtıyormuş, sınıfın içinde bay bay yapmaları el sallamaları gibi hareketler de bulunuyormuş (Katılımcı 1)" şeklindeki açıklaması ile sahip olunan bireysel farklıığın sınıf ortamındaki etkisine vurgu yapmaktadır. Katılımcı 5 şöyle ifade etmektedir: "Çok fazla takıntılı davranışları olan öğrencilerin davranışları arkadaşlarının farkındalığıyla azalabiliyor bazen, tabi bazılarında da tetiklenebiliyor (Katılımcı 5)" şeklindeki ifadesi ile kaynaştırma eğitiminin sağladığı sosyal ortamın bireysel farklılıklara iki yönlü etkisine vurgu yapmaktadır.

Sınıf/Öğretmen seviyesi; Bu tema kaynaştırma eğitimi uygulamalarında öğretmen özellikleri, çocuğun bilgisi, ilişkilerde iletişim ve güven, çocuğun kapasitesini arttıran aktiviteler, sosyal ilişkileri destekleyen aktiviteler, çocuğun değişken durumlarında planlanan aktiviteler, bireyselleştirilmiş programlar, OSB'ye özgü adaptasyonlar ve uygulama planları kodlarını içermektedir. Bu seviyeye ilişkin katılımcı 4 şöyle bahsetmektedir: "Oğlumun bundan önceki öğretmeni çok iyi bir öğretmendi ancak oğluma faydalı olmadı. Onu sınıf arkadaşları ile kaynaştıramadı, hep silik gördüler yokmuş gibi davrandılar öğretmeni de böyle davrandı ancak biz şuan ki öğretmenine geçince bizim için her şey olumlu yönde bambaşka oldu (Katılımcı 4)" şeklindeki ifadesi ile öğretmen öğrenci arasındaki ilişki, öğretmenin özellikleri ve bu konuya primer katkısına değinmiştir.

Okul seviyesi; Bu tema altında akran ilişkileri ve OSB'li olmayan çocuklarla sosyalizasyon için fırsatlar, okulun kültürel yapısı, okul yönetimi ve destek personeli, okul kuralları, öğrenme çevresi, sınıf geçmenin planlamaları, personel sürekliliği, referans ya da ek hizmetler ve sınıf mevcudu kodlarını içermektedir. Bu seviyeye ilişkin katılımcı 5 “Kesinlikle çok kötü, hiç iyi şeyler düşünmüyorum 
(Katılımcı 5)" ifadesi ile görüşünü bildirmektedir. Katılımcı 2: "Okulun yönetim kadrosu hiç yardımcı değil okul müdürü hiç istemiyor. Çocuklara o zaten "raporlu" gözüyle bakıyorlar" şeklindeki açıklaması ile okul personelinin farkındalığının olmayışı ve olması gereken pozitif ilişkinin aile ve çocukla sağlanamadığını ortaya koyuyor. Katılımcı 6: "Biz okul değerlendirmeleri için okullara gidiyoruz. Özel okullarda bile; bu konuda ayrıca eğitim almış öğretmenler de bile aslında ne kadar eksiklik olduğunu görüyoruz. Biz bu süreçte sürekli program hazırlıyor, görüşmeler yapıyoruz bu süreç interdisipliner ekip işi ancak bu doğrultuda ilerlendiği zaman ilerleme görüyoruz çocukta (Katılımcı 6). "şeklindeki ifadesi ile okul profesyonelleri ve konu paydaşı uzmanların arasındaki ilişkinin kaynaştırma eğitiminin

uygulanmasındaki

rolünü

vurgulamaktadır.

Toplumsal seviye; Bu tema engelli yasaları ve politikaları, ebeveynlerin maddi desteği ve okul kaynakları kodlarını içermektedir. Bu seviyeye ilişkin katılımcı 3 şöyle açıklamaktadır: "Benim çocuğumun yasal hakkı olmasına rağmen destek eğitim odasının açılması için ciddi çaba sarf etmek zorunda kaldım. Okul yönetimi mevzuatı bilmiyor bu konuda mevzuat şöyle diyor bu prosedür böyle uygulanacak diye bir eğitim almalı tüm yönetici personel (Katılımcı 3)." Şeklindeki ifadesi ile yasal kuralların var oluşuna pozitif bir geri bildirimde bulunurken uygulama anlamında henüz aşılamamış sorunlar olduğunu belirtmektedir.

Tablo 1: Katılımcı ebeveyn profilleri

\begin{tabular}{cccccc}
\hline Katıımcı & Yaşı & Eğitim Durumu & Çocuğunun yaşı & $\begin{array}{c}\text { Çocuğun cinsiyeti } \\
\text { Kaynaştırma eğitim } \\
\text { süresi }\end{array}$ \\
\hline Katıımcı 1 & 42 & Üniversite & 8 & $\mathrm{E}$ & 2 \\
Katılımcı 2 & 39 & İlkokul & 6 & $\mathrm{E}$ & 1 \\
Katıımcı 3 & 46 & Lisansüstü & 13 & $\mathrm{~K}$ & 2 \\
Katılımcı 4 & 34 & İlköğretim & 11 & $\mathrm{E}$ & 5
\end{tabular}

Tablo 2: İçerik analizi sonucu elde edilen temalar ve onlara ait kodlar

\begin{tabular}{|c|c|}
\hline Bireysel Düzey & - $\quad$ Çocuğun özellikleri \\
\hline Öğretmen/Sınıf Düzeyi & $\begin{array}{ll}\text { - } & \text { Öğretmen özellikleri } \\
\text { - } & \text { Otizmde öğrenme } \\
\text { - } & \text { Çocuğun bilgisi } \\
\text { - } & \text { İlişkilerde iletişim ve güven } \\
\text { - } & \text { Çocuğun kapasitesini arttıran aktiviteler } \\
\text { - } & \text { Sosyal ilişkileri destekleyen aktiviteler } \\
\text { - } & \text { Çocuğun değişken durumlarında planlana aktiviteler } \\
\text { - } & \text { Bireyselleştirilmiş programlar } \\
\text { - } & \text { OSB'ye özgü adaptasyonlar } \\
\text { - } & \text { Planlanmış aktiviteler }\end{array}$ \\
\hline Okul Düzeyi & $\begin{array}{ll}\text { - } & \text { Akran ilişkileri ve sosyalizasyon fırsatları } \\
\text { - } & \text { Okulun kültürel yapısı } \\
\text { - } & \text { Okul yönetimi/destek personeli } \\
\text { - } & \text { Okul kuralları } \\
\text { - } & \text { Öğrenme çevresi } \\
\text { - } & \text { Sınıf geçmenin planlamaları } \\
\text { - } & \text { Personel sürekliliği } \\
\text { - } & \text { Sınıf mevcudu } \\
\text { - } & \text { Referans ya da ek hizmetler }\end{array}$ \\
\hline Toplumsal Düzey & $\begin{array}{ll}\text { - } & \text { Engelli yasaları, politikaları ve uygulamaları } \\
\text { - } & \text { Okul kaynakları } \\
\text { - } & \text { Ebeveyn maddi desteği }\end{array}$ \\
\hline
\end{tabular}




\section{TARTIŞMA}

Araştırmamız kapsamında yapılan görüşmeler sonucunda elde edilen veriler bireysel seviye, sınıf/öğretmen seviyesi, okul seviyesi ve toplumsal seviye olmak üzere dört tema altında toplanmıştır.

Bu kapsamda "Oğlum sadece biraz dikkat dağıtıyormuş, sınıfın içinde bay bay yapmaları el sallamaları gibi hareketler de bulunuyormuş (Katıımcı 1)" şeklindeki ifade bireysel özelliklere ebeveyn bakış açısına bir örnek oluşturmaktadır. Araştırmamızda kaynaştırma eğitiminde bireysel seviye teması altında; ebeveynler çocuğun özelliklerindeki farklııkların öğretmen bakış açısını etkilediği görüşüne vurgu yapmışlardır. Literatürde konsantre olabilmek, komutları anlayabilmek gibi bireysel yeteneklerin ebeveynler tarafından başarıı bir kaynaştırma eğitimi için ön koşul olarak nitelendirilmekte olduğu belirtilmektedir (Trillingsgaard \& Sørensen, 1994).

Kaynaştırma eğitimi uygulamalarında çocukların bireysel davranış problemleri olumsuz bakış açısının oluşmasına zemin hazırlayabilmektedir. Katılımcı 3' ün " Biz kaynaştırmaya ilk başladığımızda kızım sınıfa uyumsuzluk yaşadı, rahatsız olmuştu o anda ilk uyumsuzluğu gidermek adına öğretmeni hiçbir şey yapmadı. Bu durum öğretmende olumsuz bir etki yarattı ve bunu aşmakta çok zorlandık" şeklindeki ifadesi çocuğun mevcut durumuna öğretmenin yaklaşımına bir örnek teşkil etmekte olup literatürden elde edilen çocukların kompleks intiyaçları ya da zor davranışlarının var olduğu durumlarda öğretmenlerin daha az ilgilenme eğiliminde olduğu bilgisini desteklemektedir (Avramidis \& Norwich, 2002).

Araştırma sonucumuzda kaynaştırma eğitiminde sınıf/öğretmen teması altında öğretmen özellikleri hem aileler hem de uzmanlar tarafından ön planda tutulan bir başlık olmuştur. Literatürde başarılı bir kaynaştırma için dikkatlerin çocuğun sahip olduğu özelliklerde olduğu ancak bu dikkatin çocuğun yerleştirildiği çevreye kaydırılması gerektiğinden ve kaynaştırma eğitimi çerçevesinde öğretmenin OSB hakkındaki bilgisi, iyi iletişim becerileri, öğrenci hakkında daha fazla bilgi sahibi olma isteğinden çevrenin parametreleri olarak bahsedilmektedir (Starr, Foy, Cramer, \& Singh, 2006). Bu kapsamda katılımcı 4' ün 'Eğer öğretmeni umursamaz ve hak yiyen biri olsaydı oğlum kaynaştırma öğrencisi olarak bu konumda olmayabilirdi. Bir örnek vereyim siz anlayın isterseniz oğlumun öğretmeni Türkçe okumalarında okuma yerine tiyatro yapıyor. Bütün çocuklar tiyatro drama şeklinde paragrafı oğluma anlatıyorlar. Kaynaştırmanın da amacı bu aslında bir şeyleri hep birlikte yapabilmek" şeklinde ifadesi ile öğretmenin kaynaştırma eğitimindeki hayati rolü literatürle paralellik gösterecek şekilde örneklendirilmiş olmaktadır (Kargın, T., Acarlar, F., \& Sucuoğlu, B., 2003)

Araştırmamızda sınıf seviyesinden sonra en çok vurgu okul seviyesindeki uygulamalar kapsamında gerçekleştirilmiştir. Bu noktada deneyimlerin şekillenmesinde özellikle okul yöneticilerinin tutumları ve ekibin iş birliği belirleyici faktör niteliğinde olduğu sonucuna varılmıştır.

Araştırmamızda okul seviyesinde kaynaştırma gerekliliklerinden okul yöneticilerinin sahip olduğu olumsuz bakış açısı ve tutumları ve ekip çalışması olmamasına bu seviyede en temel problemler olarak tanımlanmıştır. Bu kapsamda literatürde okul yöneticilerinin gelişimsel problemi olan çocuklara yönelik olumsuz tutum sergilediklerini belirten çalışma sonuçları ile paralellik göstermektedir (Kargın, T., Acarlar, F., \& Sucuoğlu, B. 2003; Rose \& Smith, 1992).

Literatürde okulların kaynaştırma eğitimi için kullanılabilir bir çevre oluşturmak, pozitif akran ilişkileri, dışlanmasının engellenmesi ve destek ekibinden yardım alınması noktalarında önemli olduğu belirtilmekte olup bu kapsamda okul yöneticileri, öğretmen ve terapistlerin işbirliği vurgulanmaktadır (Falkmer et al., 2015). Araştırma sonuçlarımızda bu kapsamda Katıımcı 6'nın kendisinin işbirlikçi uygulamaları olduğunu belirtmesine rağmen bu uygulamaların sınırlı sayıda olması kaynaştırma eğitimi uygulamaları kapsamında limitasyonları açıklayabilmektedir.

Sonuçlarımızda var olan yasal hakların uygulanması ve faaliyete geçirilmesi aşamasındaki eksiklikler toplumsal seviye teması altında özellikle vurgulanmakta olan parametrelerdir. Politikaların anlaşılması ve uygulanmasında problemlerin mevcut olduğunun altı çizilmektedir. Katılımcı 3' ün: "Okullardaki personele eğitim şart; bu sınıf şöyle açılacak mevzuat şu gibi bir eğitim" şeklindeki ifadesi ile yasal sürecin uygulanmasında uygulama ekibinin eksik bilgisi ve uygulama prosedürlerinin açık olmayışı vurgulanmakta olup bu kapsamda literatürde de yasalar ve politikaların anlaşılamadığı belirtilmektedir. Literatürde bu duruma tavsiye olarak yasalar ve politikaların mesleki dilden daha uzak daha açıklayıcı yazılması gerekliliğinden bahsedilmektedir (Falkmer et al., 2015, Renty \& Roeyers, 2006). 
Araştırma sonuçlarımızdan elde edilen bilgiler ışığında kaynaştırma eğitiminde toplumsal bakış açısının iyileştirilmesi yönünde çalışmalar yapılması gerektiği ortaya çıkmıştır. Ek olarak sadece bireysel eğitim programları değil bireyselleştirilmiş bir kaynaştırma programı intiyacı ortaya koyulmuştur. Çocuğun bireysel ihtiyaçları ve davranış şekillerinin belirlenmesi ve bu alanda çalışan meslek gruplarının bu konuda bilgilendirilmesi ile kaynaştırma eğitiminde kalitenin artırılabileceği düşünülmektedir.

Çalışmamızda dahil edilen uzman ve ebeveyn sayısının sınırlı olması, görüşülen meslek gruplarının kaynaştırma eğitimi uygulamalarında çalışmakta olan ekibin tüm üyelerinin içermemesi ve bu nedenle kaynaştırma eğitimini daha bütüncül değerlendirebilme intimalimizi azaltmış olması çalışma limitasyonlarımızdır.

İleride yapılacak araştırmalar için kaynaştırma eğitiminin daha iyi değerlendirilebilmesi, anlaşılması ve planlanmasına yardımcı olmasını sağlamak amacıyla daha çok ebeveyn ve uzman ile görüşme yapılması önerilmektedir. Elde edilecek bilgiler uygulama paydaşlarının farkındalığının artırılması içinde önemli bir niteliğe sahip olacaktır. Ayrıca kaynaştırma eğitimi uygulamalarında ebeveynlerin ve çocuğun etkileşim içinde bulunduğu tüm grupların dahil edilmesine dikkat edilmesi gerekmektedir.

\section{Kaynaklar}

Association, A. P. (2013). Diagnostic and statistical manual of mental disorders (DSM-5®): American Psychiatric Pub.

Akalin, S., Demir, S., Sucuoglu, B., Bakkaloglu, H., \& Iscen, F. (2014). The Needs of Inclusive Preschool Teachers about Inclusive Practices. Eurasian Journal of Educational Research, 54, 39-60.

Avramidis, E., \& Norwich, B. (2002). Teachers' attitudes towards integration/inclusion: a review of the literature. Eur J Spec Needs Educ, 17(2), 129-147.

Batu, E. S. (2000). Kaynaştırma, destek hizmetler ve kaynaştırmaya hazırlık etkinlikleri. Ankara Üniversitesi Eğitim Bilimleri Fakültesi Özel Eğitim Dergisi, 2(04), 3545.

Bilaver, L. A., Cushing, L. S., \& Cutler, A. T. (2016). Prevalence and correlates of educational intervention utilization among children with autism spectrum disorder. J Autism Dev Disord, 46(2), 561-571.
Çetinkaya, Ç., \& Döner, İ. (2012). Türkiye'de üstün yeteneklilere tanınan hakların incelenmesi. Sakarya University Journal of Education, 2(3), 7-20.

Erden, G., Akdur, S., Angın, E., Er, E., Aslan, B. (2014). Otizm Spektrum Bozukluğu. Ankara: Aile ve Sosyal Politikalar Bakanlığı

Falkmer, M., Anderson, K., Joosten, A., \& Falkmer, T. (2015). Parents' Perspectives on Inclusive Schools for Children with Autism Spectrum Conditions. Intl J Disabil Dev Educ, 62(1), 1-23.

Girli, A. (2007). Asperger sendromlu ve yüksek işlevli otistik çocukların eğitimden yararlanma düzeyleri. Ankara Üniversitesi Eğitim Bilimleri Fakültesi Özel Eğitim Dergisi, 8(02), 23-43.

Kargın, T. (2004). Kaynaştırma: tanımı, gelişimi ve ilkeleri. Ankara Üniversitesi Eğitim Bilimleri Fakültesi Özel Eğitim Dergisi, 5(02), 1-13.

Kargın, T., Acarlar, F., \& Sucuoğlu, B. (2003). Öğretmen, yönetici ve anne-babaların kaynaştırma uygulamalarına ilişkin görüşlerinin belirlenmesi. Ankara Üniversitesi Eğitim Bilimleri Fakültesi Özel Eğitim Dergisi, 4(02), 055076.

Koçyiğit, S. (2015). Ana sınıflarında kaynaştırma eğitimi uygulamalarına ilişkin öğretmen-rehber öğretmen ve ebeveyn görüşleri. Uluslararası Türkçe Edebiyat Kültür Eğitim (TEKE) Dergisi, 4(1), 391-415.

Renty, J., \& Roeyers, H. (2006). Satisfaction with formal support and education for children with autism spectrum disorder: The voices of the parents. Child Care Health Dev, 32(3), 371-385.

Rose, D. F., \& Smith, B. J. (1992). Attitude Barriers and Strategies for Preschool Mainstreaming. Policy and Practice in Early Childhood Special Education Series, 161-181.

Starr, E. M., Foy, J. B., Cramer, K. M., \& Singh, H. (2006). How are schools doing? Parental perceptions of children with autism spectrum disorders, Down syndrome and learning disabilities: A comparative analysis. Educ Train Dev Disabil, 315-332.

Trillingsgaard, A., \& Sørensen, E. U. (1994). School integration of high-functioning children with autism. A qualitative clinical interview study. Eur Child Adolesc Psychiatry, 3(3), 187-196.

Ulutaşdemir, N. (2007). Engelli çocukların eğitimi. Fırat Sağlık Hizmetleri Dergisi, 2(5), 119-130. 